\title{
SIMULTANEOUS LIDAR AND AIRGLOW TEMPERATURE MEASUREMENTS IN THE MESOPAUSE REGION
}

\author{
J. R. Yu, H. Latifi, and C. Y. She
}

Department of Physics, Colorado State University

J. H. Yee and R. J. Niciejewski

Space Physics Research Laboratory, University of Michigan

Abstract. A scientific flight over Fort Collins $\mathrm{CO}$ $\left(40.60 \mathrm{~N}, 105^{\circ} \mathrm{W}\right)$ was conducted on the night of April 1516,1990 , during the ALOHA-90 campaign. In this Colorado mission, a direct comparison between measured mesospheric $\mathrm{O}_{2}$ and $\mathrm{OH}$ rotational temperatures with the airglow instruments on board the Electra and simultaneously measured $\mathrm{Na}$ temperatures by a ground-based narrowband $\mathrm{Na}$ lidar has been made. This first comparison resulted in general agreement in measured temperatures between different instruments.

\section{Introduction}

The Colorado flight of ALOHA-90 on the night of April 15-16, 1990 was design to study wave activity near the Rocky Mountains with both ground-based and airborne instrumentations. One of the scientific objectives is to compare the values of mesospheric temperatures simultaneously measured by the University of Michigan airglow instruments on the Electra and by the ground-based Colorado State Na temperature lidar. Although both groundbased and airborne instruments had recorded about 5 hrs of data each, as shown in Figure 1, only a little over $2 \mathrm{hrs}$ of data overlapped. This is because the cloud coverage over a fixed location and the flight path occur at different times. Three triangular paths were flown [Gardner, 1991] and the times of closest approach to Fort Collins, as marked by X on the time scale, were $3.44,6.24,8.58$ and $11.24 \mathrm{hr}$. UT, April 16, 1990. Simultaneous lidar and interferometry determination of mesospheric temperatures for two such times, $6.24 \mathrm{hr}$. and $8.58 \mathrm{hr}$. UT, were available.

On this night, the Colorado State $\mathrm{Na}$ temperature lidar [She et al.,1990] was setup to measure temperature profiles at $1 \mathrm{~min}$ interval with a range-bin length of $75 \mathrm{~m}$. In order to reduce photon-noise and density variations, the photoncount profiles were spatially and temporally filtered to yield mesopause temperature profiles with $1 \mathrm{~km}$ vertical resolution in an integration period of $2.5 \mathrm{~min}$. Consecutive profiles are then averaged and reduced to one temperature profile from $83 \mathrm{~km}$ to $103 \mathrm{~km}$ every 5 min with $1 \mathrm{~km}$ vertical resolution. The absolute temperature accuracies are estimated to be \pm 3 $K$ and $\pm 5 K$ respectively at the peak and at $\pm 5 \mathrm{~km}$ from the peak of the $\mathrm{Na}$ layer. The detailed experimental and data analysis procedures have been given in a separate publication [She et al., 1991(a)].

The University of Michigan had two airglow instruments on board the Electra: an Ebert-Fastie spectrometer and a Michelson interferometer. On this night, the Ebert-Fastie spectrometer measures the intensities and rotational temperatures of the $\mathrm{O}_{2}$ Atmospheric (0-1) and $\mathrm{OH}$ Meinel (7-3) bands. The Michelson interferometer measures the intensities and rotational temperatures of the $\mathrm{OH}$ Meinel (3-1) band.

Copyright 1991 by the American Geophysical Union.

Paper number 91GL01153

0094-8534/91/91GL-01153\$3.00

\section{Experimental Results}

Figure 1 shows the measured $\mathrm{O}_{2}$ and $\mathrm{OH}$ airglow intensities along with $\mathrm{Na}$ abundance. Due to the tifference in vibrational transitions used, the emission intensities of the two $\mathrm{OH}$ bands are different [Yee et al., 1991]. Rotational temperatures of the $\mathrm{O}_{2}$ atmospheric $(0-1)$ band, $\mathrm{OH}$ Meinel (7-3) band and $\mathrm{OH}$ Meinel (3-1) band taken by the University of Michigan airborne airglow instruments are compared in Figure 2. Except the narrow peak near $8.7 \mathrm{hr}$. UT measured by the Ebert-Fastie spectrometer, mesopause temperatures from $5 \mathrm{hr}$. to $10 \mathrm{hr}$. UT varied around $200 \mathrm{~K}$ with minor features masked by the error bars. Depending on

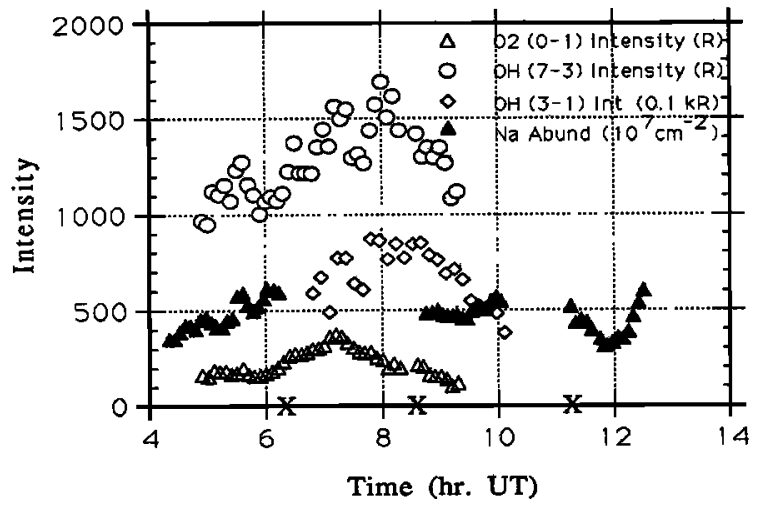

Fig. 1 Temporal distribution of intensities of $\mathrm{O}_{2}$ and $\mathrm{OH}$ nightglow and $\mathrm{Na}$ aboudance for April 16, 1990, showing over 2 hrs of data overlap between lidar and airglow measurements. Times of closest approach to Fort Collins, $6.24,8.58$, and $11.24 \mathrm{hr}$. UT are marked by $\mathrm{X}$ on the time axis.

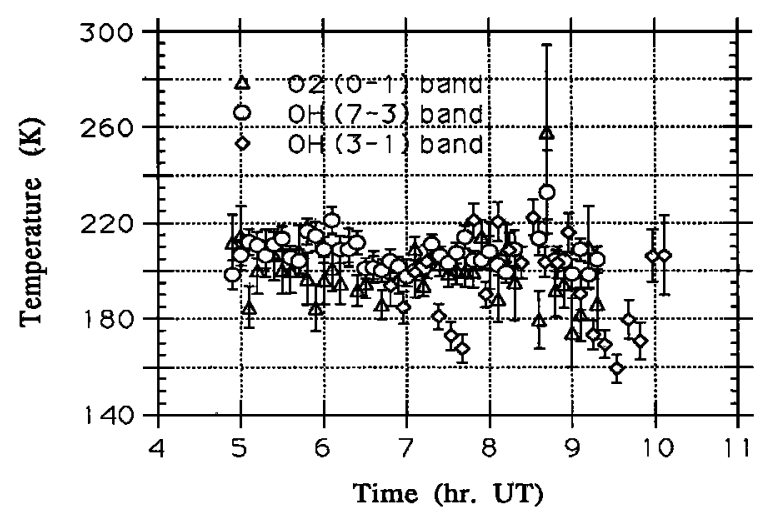

Fig. 2 Temporal mesospheric temperatures measured by airglow instruments via $\mathrm{O}_{2}(0-1), \mathrm{OH}(7-3)$ and $\mathrm{OH}(3-1)$ bands during the nightglow of April 16, 1990 near Fort Collins, CO. 
the detected intensity, the temperature uncertainty for a 5 to $10 \mathrm{~min}$. integration time is typically $\pm 10 \mathrm{~K}$. In general, both the accuracy and agreement of the three rotational temperatures improved in the region of high airglow intensities near 7-8 hr. UT. Again, the rotational temperatures measured by the two $\mathrm{OH}$ bands differ somewhat, with higher temperatures being recorded for the (7-3) band [Niciejewski and Yee, 1991].

Figure 3 shows the temperatures measured by Colorado State $\mathrm{Na}$ temperature lidar. The averaged centroid height of the $\mathrm{Na}$ layer that night was $92.5 \mathrm{~km}$. The temperatures at three altitudes of $97.5 \mathrm{~km}, 92.5 \mathrm{~km}$ and 87.5 $\mathrm{km}$ are the result of a moving average using a Gaussian weighting function of $10-\mathrm{km}$ full-width at $92.5 \mathrm{~km}$ and of $5-$ $\mathrm{km}$ full-width at $97.5 \mathrm{~km}$ and $87.5 \mathrm{~km}$, resulting in temperature uncertainties of $\pm 3 \mathrm{~K}$ and $\pm 5 \mathrm{~K}$ respectively. The three points near $8.8 \mathrm{hr}$. UT are exceptions where the errors are roughly doubled because of poorer signal due to partial cloud coverage. It is evident that the averaged temperatures of the two higher altitudes are relatively constant changing from $200 \mathrm{~K}$ between 4.0 to $6.0 \mathrm{hr}$. U'T (9:00 to 11:00 p.m., MST) to slightly lower than $190 \mathrm{~K}$ after $9.0 \mathrm{hr}$. UT. The temperatures below the Na centroid was much colder (as low as 170 K) between 9:00 to 11:00 p.m., MST and then warmed up to the temperatures of the rest of the $\mathrm{Na}$ layer with somewhat bigger fluctuations. Although the temperature uncertainty near $8.8 \mathrm{hr}$. UT is larger, the anomalously high readings for all three altitudes at this time appear to be real.

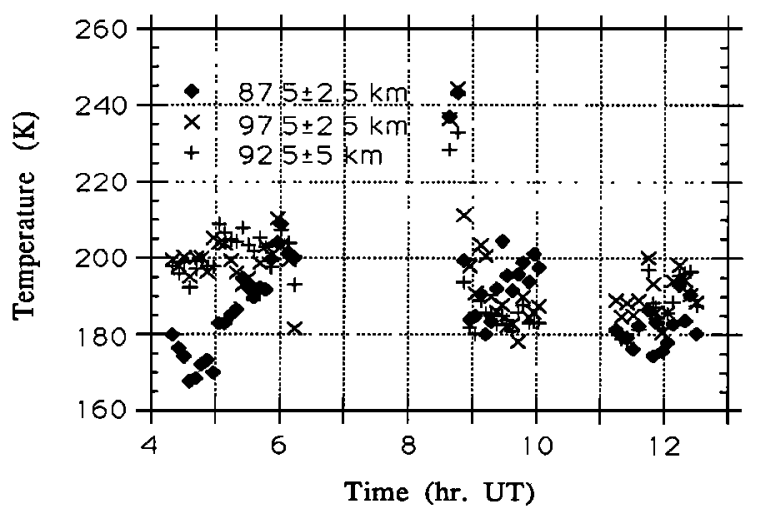

Fig. 3 Temporal mesospheric temperatures at altitudes of $87.5 \mathrm{~km}, 92.5 \mathrm{~km}$ and $97.5 \mathrm{~km}$ measured by narrowband $\mathrm{Na}$ lidar on April 16, 1990 at Fort Collins, CO.

\section{Comparisons and Discussion}

It is unfortunate that due to local cloud coverage, lidar data were not available form $6.3 \mathrm{hr}$. to $8.5 \mathrm{hr}$. UT when the airglow intensities were high. However, there are more than two hours of data overlap between the ground-based lidar and the airborne airglow instruments which form the basis of an viable first comparison.

It is well known that, on the average, the $\mathrm{O}_{2}$ airglow originates from near $95 \mathrm{~km}$ altitude [McDade et al., 1986] and $\mathrm{OH}$ from near $87 \mathrm{~km}$ altitude [Baker and Stair, 1988], each with a layer thickness of about $10 \mathrm{~km}$. We compare the airglow $\mathrm{O}_{2}$ measurements with lidar temperatures at these altitudes averaged over a Gaussian weighting function with a $10-\mathrm{km}$ full-width at $95 \mathrm{~km}$ and a $5-\mathrm{km}$ full-width at 87.5 $\mathrm{km}$. The reason for chosen a narrower width at $87.5 \mathrm{~km}$ is due to larger lidar temperature errors at altitudes below 83 $\mathrm{km}$. Figure 4 compares these measurements between 5.0 and 10.0 hrs., UT, April 16, 1990. Within the experimental errors, the $\mathrm{O}_{2}$ airglow temperatures seem to track the lidar

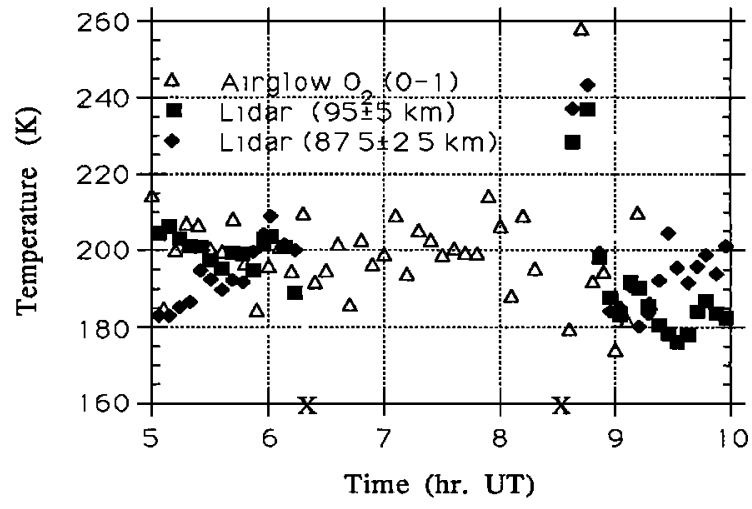

Fig. 4 Rotational temperatures of the $\mathrm{O}_{2}(0-1)$ band compared with $\mathrm{Na}$ lidar temperatures at $95 \mathrm{~km}$ and $87.5 \mathrm{~km}$. Times of closest approach to Fort Collins, 6.24 and $8.58 \mathrm{hr}$. UT are marked by $\mathrm{X}$ on the time axis.

temperatures at $95 \mathrm{~km}$. We note that this general agreement includes the sharp temperature rise near $8.7 \mathrm{hr}$. UT, and that one of the Electra's closest approach to Fort Collins, as marked by a $X$ on the time axis, took place at $8.58 \mathrm{hr}$.UT. As shown in Figure 2, airglow OH (7-3) temperatures are comparable to the $\mathrm{O}_{2}$ temperatures within the error bars. Compared to the airglow data, the available lidar temperatures at $87.5 \mathrm{~km}$ are clearly colder before $5.5 \mathrm{hr}$. UT and somewhat warmer after $9.5 \mathrm{hr}$. UT, suggesting that the $\mathrm{OH}$ layer this night might have been higher than usual. A comparison between $\mathrm{OH}$ data from both airglow instruments and $\mathrm{Na}$ temperatures at $95 \mathrm{~km}$ and $87.5 \mathrm{~km}$ altitudes averaged over a Gaussion weighting function with $5-\mathrm{km}$ fullwidth is shown in Figure 5. Compared to the available $\mathrm{OH}$ (3-1) band data, the OH (7-3) band temperatures are in general higher [Niciejewski and Yee, 1991]. The OH (3-1) band temperatures between $9-10 \mathrm{hr}$. UT are closer to the lidar values at $95 \mathrm{~km}$ than those at $87.5 \mathrm{~km}$, again suggesting a higher $\mathrm{OH}$ layer.

In summary, the first comparison of simultaneous mesopause temperature measurements between $\mathrm{Na}$ temperature lidar and airglow instruments have been made near Fort Collins, $\mathrm{CO}\left(40.6^{\circ} \mathrm{N}, 105^{\circ} \mathrm{W}\right)$ as a part of ALOHA90 campaign. Despite the differences in angular views between ground-based lidar ( $1 \mathrm{mrad}$.) and airborne airglow instruments (30 mrad.), the measured temperatures agreed within the error bars of the instruments. A narrow high temperature feature near a time of closest approach to Fort

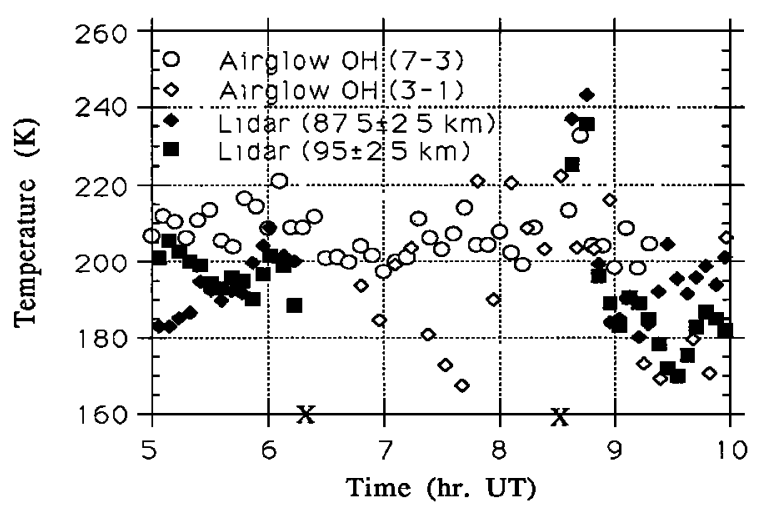

Fig. 5 Rotational temperatures of the $\mathrm{OH}(7-3)$ and $\mathrm{OH}$ (31) bands compared with $\mathrm{Na}$ lidar temperatures at $95 \mathrm{~km}$ and $87.5 \mathrm{~km}$. Times of closest approach to Fort Collins, 6.24 and $8.58 \mathrm{hr}$. UT are marked by $\mathrm{X}$ on the time axis. 
Collins ( $8.58 \mathrm{hr}$. UT) were detected by both the lidar and the Ebert-Fastie spectrometer at $8.7 \mathrm{hr}$. UT, April 16, 1990. Lidar measurements show temperature differences between Na layers centered at $95 \mathrm{~km}$ and $87.5 \mathrm{~km}$. This difference coupled with the lack of gross differences between $\mathrm{O}_{2}$ and $\mathrm{OH}$ temperatures suggests that the $\mathrm{OH}$ layer might have been much higher that night than its known average. This is consistent with rocket data which showed a mean half-width of $12 \mathrm{~km}$ [Baker and Stair, 1988]. Indeed, compared to the available lidar temperatures on March 3,1990, the measured lidar temperatures at $87.5 \mathrm{~km}$, on the average, were much colder on April 16, 1990 [She et al., 1991(b)]. Continued simultaneous and co-located mesopause temperature measurements between lidar and airglow instruments with lower measurement uncertainty will not only permit studies of temperature variations within 5-K range but also permit investigations of the layer heights of mesopause radicals, such as $\mathrm{O}_{2}$ and $\mathrm{OH}$, and their variabilities. In fact, such a campaign using Western Ontario's Michelson interferometer which has a temperature error of $\pm 1 \mathrm{~K}$ [Turnbull and Lowe, 1991] and Colorado State's Na temperature lidar already took place in March 1991.

Acknowledgements. The work of the Colorado State University group was supported in part by NSF Grant ATM 88-20452. The work of the University of Michigan group was supported in part by NSF Grants ATM-88-22530 and ATM 89-01367.

\section{References}

Baker, D. J. and A. T. Stair, Jr., Rocket measurements of the altitude distributions of the hydroxyl airglow, Physica Scripta 37, 611-622, 1988.

Gardner, C. S., Introduction to ALOHA-90: the airborne lidar and observations of the Hawaiian Airglow Campaign, Geophys. Res. Lett., this issue, 1991.

McDade, I. C., D. P. Murtagh, R. G. H. Greer, P. H. G. Dickinson, G. Witt, J. Stegman, E. J. Lliwellyn, L.
Thomas and D. B. Jenkins, ETON 2: Quenching parameters for the proposed precursors of $\mathrm{O}_{2}\left(\mathrm{~b}_{1} \mathrm{~S}_{\mathrm{g}}{ }^{+}\right)$ and $O(1 S)$ in the terrestrial nightglow, Planet. Space Sci. 34, 789, 1986.

Niciejewski, R. J., and J. H. Yee, Airglow rotational temperature measurements during ALOHA-90 campaign, Geophys. Res. Lett., this issue, 1991.

She, C. Y., H. Lafiti, J. R. Yu, R. J. Alvarez II, R. E. Bills and C. S. Gardner, Two-frequency lidar technique for mesospheric Na temperature measurements, Geophys. Res. Lett. 17, 929-932, 1990.

She, C. Y., J. R. Yu, H. Lafiti and R. E. Bills, High spectral resolution fluorescence lidar for mesospheric sodium temperature measurements, submitted to Applied Optics, 1991(a).

She, C. Y J. R. Yu, J. W. Huang and C. Nagasawa and C. S. Gardner, $\mathrm{Na}$ temperature lidar measurements of gravity wave perturbations of wind, density and temperature in the mesopause region, Geophys. Res. Lett., this issue, 1991(b).

Turnbull, D. N. and R. P. Lowe, Temporal distribution in the hydroxyl nightglow observations during ALOHA-90 campaign, Geophys. Res. Lett., this issue, 1991.

Yee, J. H., R. J. Niciejewski and M. Z. Luo, Observations of $\mathrm{O}_{2}$ (1S) and $\mathrm{OH}$ nightglow during ALOHA-90 Campaign, Geophys. Res. Lett., this issue, 1991.

J. R. Yu and C. Y. She, Department of Physics, Colorado State University, Fort Collins, CO 80523

$H$. Latifi is now at Industrial University of Shariff, Tehran, Iran.

J. H. Yee and R. J. Niciejewski, Space Research Bldg., the University of Michigan, 2455 Hayward Street, Ann Arbor, MI 48109-2143

Received: April 2, 1991

Accepted: April 23, 1991 